\title{
Do people have control over the decisions they make? Psychometric properties of the Italian version of the free will and scientific determinism questionnaire (FAD-plus-I)
}

\author{
Emanuele Fino $^{1}$ (D) Paolo lliceto $^{2}$ \\ Accepted: 26 August 2021 \\ (C) The Author(s) 2021
}

\begin{abstract}
The FAD-Plus is a multidimensional measure of lay Beliefs in Free Will, Fatalistic Determinism, Scientific Determinism, and Unpredictability. This study had four aims: First, to test the factor structure of the Italian translation of the FAD-Plus in a sample of adults from the community, using structural equation modeling. Second, to test the reliability of the four scales. Third, to investigate gender invariance in item thresholds and factor loadings. Fourth, to analyze the criterion-related validity of the measure. Participants were 328 adults from the community, specifically 173 females and 155 males aged 18-56 years. Results showed that the proposed bifactor model tested by means of exploratory structural equation modeling fitted the data well $(\mathrm{CFI}=1.000$, RMSEA $=0.000$, SRMR $=0.045)$, and that all the scales were reliable (Omega $=.91-.98)$. Gender invariance was established, with no significant differences in fit indices between females and males. Beliefs in Free Will correlated positively and lowly to moderately with Aggressiveness $\left(r_{s}=.12\right)$, Extraversion (.25), Self- (.40) and Other-Representations of adult attachment (.43). Beliefs in Fatalistic Determinism correlated positively and lowly with Other-Representations $\left(r_{s}=.11\right)$, whereas its correlations with Aggressiveness, Extraversion, and Neuroticism were close to zero. In conclusion, these findings provide researchers and practitioners with evidence on a reliable and valid measure of Beliefs in free will and determinism in the Italian context, considered as predictors of individuals' autonomy, effective coping, and prosocial behavior, of foremost importance for prevention and intervention in the community, particularly in occupational, legal, and clinical settings.
\end{abstract}

Keywords Free will $\cdot$ Scientific determinism $\cdot$ Gender invariance $\cdot$ Personality traits $\cdot$ Structural equation modeling

\section{Introduction}

Individuals who believe that they have little or no power over the course of their actions are more likely to behave irresponsibly, aggressively, and anti-sociallythan those who believe in free will (Baumeister \& Monroe, 2014). Deterministic beliefs can dramatically impact self-control (Muraven, 2010), leading to several implications for physical and mental health. On the other hand, believing in free will supports individuals in coping with life stressors and enhances their confidence in the

Emanuele Fino

emanuele.fino@ntu.ac.uk

1 Department of Psychology, Nottingham Trent University, Nottingham NG1 4FQ, UK

2 S\&P Statistics and Psychometrics Ltd, Rome, Italy ability to adjust to new ways of living, seek treatment when needed, and work towards improving their health and wellbeing (Baumeister, 2017). In this vein, previous research indicated that measuring Beliefs in Free Will (BFW) and beliefs in determinism is of foremost importance for health prevention and intervention in the community (Rigoni et al., 2016; Vonasch et al., 2017).

\section{Definitions and Theoretical Models of Beliefs in Free Will and Determinism}

In the last two decades, there has been an increase in psychological research on individuals' BFW and determinism, leading to the development of different definitions and theoretical models (Baumeister et al., 2009). A widely accepted definition of lay BFW refers to an individual's perceptions of freedom to act to make decisions (Baumeister \& Monroe, 2014). Conversely, the definition of beliefs in determinism refers to 
an individual's perceptions of events as established a priori, involving null to limited freedom over the course of their decisions and their agency (Li et al., 2018). Stroessner and Green (1990) argued that BFW and beliefs in determinism coexist at the individual's level. In the same vein, according to Pauhlus and Carey (2011), two different types of beliefs in determinism coexist to BFW, namely Beliefs in Fatalistic Determinism (BFD) and Beliefs in Scientific Determinism (BSD). BFD imply believing that fate rules over people's lives, restricting their potential to act and their power to make decisions. On the other hand, BSD refer to believing in the power of biological and environmental factors in shaping individuals and their personality, thus playing a decisive role in orienting their life choices. Lastly, the authors defined Beliefs in Unpredictability (BUP) as an individual's perception of life events as governed by randomness, and the perceived difficulty of making predictions over their course. They further hypothesized that BUP coexist to BFW, BFD, and BSD.

Research has attempted to define and measure BFW and beliefs in determinism since the eighties of the past century (Stroessner \& Green, 1990). However, such attempts showed at least two major limitations: (i) they considered only a small set of the variables that account for BFW and beliefs in determinism, and (ii) they were based on strict a priori assumptions on such beliefs, for example that BFW and beliefs in determinism are not compatible and do not coexist at the individual's level. More recently, in the attempt to overcome such limitations, Paulhus and Carey (2011) have developed a multidimensional theoretical model of BFW, BFD, BSD, and BUP. The model assumed that the four types of beliefs are not incompatible and that each can be observed and measured. In particular, the authors hypothesized and confirmed in their study that the four dimensions are orthogonal, except for BFD and BSD, and for BFD and BUP.

\section{The Free Will and Scientific Determinism Questionnaire (FAD-Plus)}

To measure such dimensions, Paulhus and Carey (2011) developed the Free Will and Scientific Determinism Questionnaire (FAD-Plus), a 27-item self-report scale underlying a four-factor structure of BFW, BFD, BSD, and BUP. The scale was originally validated in two samples of undergraduate students and one community sample. The adequacy of the four-factor solution was confirmed in all the samples, with each scale showing satisfactory psychometric properties. Women scored significantly lower than men in BSD in both the two undergraduate samples and the community sample, whilst women scored significantly higher than men in BFW in the community sample.

Regarding the criterion-related validity of the FAD-Plus, Paulhus and Carey (2011) found correlations between the four FAD-Plus scales and the five factors of personality, although the correlations were low. They found that BFW correlated positively with Extraversion $(r=.20, p<.01)$, indicating a relation between social confidence and the belief in individuals' autonomy, and with Agreeableness $(r=.19, p<.05)$, indicating a relation between $\mathrm{BFW}$ and prosocial behavior. Moreover, BFD correlated positively with Agreeableness $(r$ $=.19, p<.05)$, suggesting that individuals endorsing such a "helpless worldview [...] may have to take on the cooperative and complaint attitudes of agreeable people" (p. 100). BFD correlated negatively with Emotional Stability $(r=-.22, p<$ .01 ), indicating a relation between such a fatalisticdeterministic worldview and a neurotic personality. To the best of our knowledge, there is no evidence on the relationship between BFW, BFD, BSD, and BUP and Activity, Aggressiveness, and Sensation Seeking from the alternative five-factor model of personality (Aluja et al., 2010).

In addition, recent research has indicated that those believing in either free will or determinism tend to express a stronger orientation towards passionate relationships (Boudesseul et al., 2016), with such beliefs potentially triggering a variety of conceptual differences and practical consequences, depending on the specific contexts and types of experience in which they may have occurred. Feltz (2015) argued that when BFW are absent, individuals tend to be more likely to experience "difficulty maintaining meaningful relationships with others and interpersonal conflicts may become more common" (p. 113). However, to the best of our knowledge, the available evidence about such relationships is scarce, requiring further investigation.

\section{The FAD-Plus in Other Linguistic and Cultural Contexts}

To date, the FAD-Plus has been successfully adapted into other languages and validated in other populations (Chinese: Li et al., 2018; French: Caspar et al., 2017; Polish: Kondratowicz-Nowak et al., 2018), confirming the adequacy of the four-factor structure in other cultural contexts, although those studies reported substantial modifications to the original measurement model.

To the best of our knowledge, to date there are no validated measures of BFW and believes in determinism available in the Italian context, and there are at least three reasons supporting the translation and validation of the FAD-Plus in the Italian context. First, results from several studies already supported the validity of the FAD-Plus in different cultural contexts, showing adequate psychometric properties. On such basis, the FAD-Plus represents a promising candidate for the measurement of BFW, BFD, BSD, and BUP in the Italian context. Moreover, the study will have emic and etic implications, potentially contributing to shed a light on the meaning and understanding of free will and determinism in the Italian context, thus enabling local researchers to compare their data to 
those from other cultural contexts. In fact, recent literature proposed that the meaning and the common understanding of free will may vary across cultures (Berniūnas et al., 2021). For example, a study using the FAD-Plus in the Chinese context (Zhao et al., 2014) showed that participants could not understand one item from the BFW scale (Item 21, "People have complete free will"), since the term was apparently not fully interpretable by those lacking expert knowledge. In the same vein, a qualitative study on free will by Lim and Chen (2018) showed that participants "did not understand what this term referred to since it was non-indigenous" (p. 895). Second, the Italian version of the FAD-Plus will allow researchers and practitioners in psychology to measure such beliefs in the Italian community, with a potentially significant impact in the social, academic, occupational, legal, and clinical settings (Clark et al., 2017). For example, it will represent an asset in the design and implementation of effective prevention and intervention strategies, particularly those targeting individuals who are more at risk to endorse deterministic beliefs which make them more exposed to dysfunctional patterns of interpersonal relationships and negative outcomes in those settings (Feltz, 2015). Third, previous literature highlighted the need for further research to confirm the factor structure of the FAD-Plus (Caspar et al., 2017; Paulhus $\&$ Carey, 2011), and research on its psychometric properties is warranted.

\section{The Current Study}

The current study had four aims: (i) to test the factor structure and construct validity of the Italian translation of the FADPlus (FAD-Plus-I) proposed by the authors of the present manuscript, in a sample of adults from the Italian community. In particular, we tested the adequacy of the measurement model reported by Paulhus and Carey (2011), consisting of four latent factors (BFW, BFD, BSD, and BUP), which we assumed to be orthogonal except for BFD and BSD, and for BFD and BUP; (ii) to test the reliability of the four scales; (iii) to test whether the scale is gender invariant in item thresholds and factor loadings; (iv) to test the criterion-related validity, and more precisely the concurrent validity of the FADPlus-I, by analyzing the correlations between the four scales and the five factors of personality from the alternative fivefactor model (Aluja et al., 2010) and Self-and OtherRepresentations of adult attachment (Candilera, 2007). Following, the hypotheses formulated and tested in the study are listed and presented in detail.

H1: The factor structure of the FAD-Plus-I confirms the adequacy of the factor structure originally developed and observed by Paulhus and Carey (2011) for the FAD-Plus. H2: The four FAD-Plus-I scales are reliable, with Omega values equal to or greater than .80 .
H3: The FAD-Plus-I is gender invariant in item thresholds and factor loadings.

H4: The FAD-Plus-I shows criterion-related validity, particularly BFW correlates positively and lowly $(\leq .3)$ to moderately (from .3 to .5 ) with Extraversion (H4a) and with Self-(H4b) and Other-Representations of adult attachment (H4c), and negatively with Aggressiveness (H4d); BFD correlates positively and lowly with Neuroticism (H4e) and with Self- (H4f) and OtherRepresentations $(\mathrm{H} 4 \mathrm{~g})$, and negatively and lowly with Aggressiveness (H4h).

\section{Methods}

\section{Procedure}

Participants were recruited from November 2018 to February 2019 at universities, markets, supermarkets, shops, banks, public parks, and post offices in different districts of two non-randomly selected Italian regions, namely Piedmont (north) and Lazio (mid). The inclusion criteria were to be at least 18 years old and to be able to read and understand Italian. Recruitment was performed by two psychology students who collaborated on the project and who approached individuals face-toface in the public spaces, verbally inviting them to take part in the study. The individuals were specified that no incentives would be offered, with participation to the study being entirely voluntary. Those who expressed their interest in the study were asked to read and understand a participant information sheet, which also served to screen candidates on their overall ability to read and understand Italian and the purposes of the study. Those who confirmed their interest in the study were then asked to read, understand, accept, and sign a written informed consent form. They were also asked for contact details, to be later contacted and met in a separate venue to complete the study procedure. The procedure consisted of filling out a set of self-reported measures in paper-and-pencil format. The order of administration was the same across all the participants. Each completed survey was associated with an alphanumeric code to guarantee the anonymity of the participants. All the participants received full debriefing following the completion of the procedure and were invited to ask any questions they may have about the study. The procedure was designed and implemented in compliance to the Code of Ethics of the World Medical Association, Declaration of Helsinki for research involving humans. The S\&P Statistics \& Psychometrics Ltd. institutional ethical committee 
reviewed the study procedure, oversaw adherence to the standards, and confirmed ethical approval.

\section{Participants}

In summary, 371 Italian-speaking adult individuals were approached, of which 26 declined the invite to participate and 17 did not complete the procedure. Overall, 328 individuals agreed to participate, completed the study procedure, and were included in the study. Those were 173 women (52.7\%) and 155 men (47.3\%), with age comprised between 18 and 56 years $(M$ $=30.4, S D=8.7)$, coming from various educational and socioeconomic backgrounds. We found no differences between women $(M=29.8 ; S D=8.2)$ and men $(M=31.1 ; S D=9.2)$ in age $\left(t_{(326)}=1.40 ; p=.16\right)$, years of education $\left(\chi_{(2)}^{2}=1.17 ; p=\right.$ $.55)$, and marital status $\left(\chi_{(1)}^{2}=1.70 ; p=.19\right)$. Table 1 summarizes the socio-demographic characteristics of participants.

\section{Measures}

A set of self-reported measures were administered to all the participants, in the following order.

The FAD-Plus-I (Paulhus \& Carey, 2011), a 27-item questionnaire measuring lay BFW (7 items, e.g., "People have complete control over the decisions they make.") and in closely related constructs, particularly BFD (5 items, e.g., "I believe that the future has already been determined by fate."), BSD (7 items, e.g., "People's biological makeup determines their talents and personality."), and BUP (8 items, e.g., "No one can predict what will happen in this world."). All the items are scored using a 5-point Likert-type scale ranging from 1 ("completely disagree") to 5 (“completely agree"). Total scale scores were obtained by summing up the relevant items. Higher scores in BFW, BFD, BSD, and BUP indicate a higher degree of endorsement of the relevant beliefs. The English version of the FAD-Plus was first independently translated into Italian by one of the authors of this paper. The adequacy of the translations was assessed independently through a backtranslation process performed by a native speaker, professional translator. In a second reconciliation phase, the original draft was compared to the back translation, looking for any discrepancies. The process led us to identify two major issues, regarding two items (Item 2 and Item 14), for which a consensus about the Italian translation that could maximize the fit to the original English version could not be achieved, thus requiring a further evaluation. For this reason, we established correspondence with one the authors of the original version of the FAD-Plus (D. H. Paulhus, personal communication, June 6, 2019), aiming to clarify the adequacy of the Italian translation of those two items to the intended meaning of their original English versions. The process led us to change the first versions of those two items: (i) regarding Item 2, because "biological makeup" is commonly and colloquially translated in Italian as "DNA", it was agreed that the latter should be preferred; (ii) regarding Item 14, because the English verb "to show" could be interpreted in Italian as either "to prove" or "to showcase", it was confirmed that the former matched the original intended meaning. The final version of the FAD-Plus-I, reflecting those changes, is reported in the Appendix, along with the scoring instructions. Regarding the reliability of the original version of the FAD-Plus, Paulhus and Carey (2011) found in their validation study that the four factors were reliable, each showing adequate Cronbach's alpha values (BFW $=.70, \mathrm{BSD}=.69, \mathrm{BFD}=.82, \mathrm{BUP}=.72)$. Regarding the
Table 1 Demographic characteristics of the participants $(N=328)$

\begin{tabular}{llcccc}
\hline & & Women $(N=173)$ & Men $(N=155)$ & Statistics & $\mathrm{p}$ \\
\hline Age & Mean $(S D)$ & $29.8(8.2)$ & $31.1(9.2)$ & $t_{(326)}=1.40$ & .16 \\
Working status & Housewives & $21(12.1)$ & 0 & $\chi_{(8)}^{2}=21.7$ & $<0.001$ \\
$\mathrm{~N}(\%)$ & University students & $22(12.7)$ & $33(21.3)$ & & \\
& Unemployed & $18(11.6)$ & $53(30.6)$ & & \\
& Industry workers & $53(30.6)$ & $18(11.6)$ & & \\
& Employees & $57(36.8)$ & $48(27.7)$ & & \\
& Retailers & $9(5.2)$ & $16(10.3)$ & & \\
& Professionals & $1(0.6)$ & $1(0.6)$ & & \\
& Entrepreneurs & $48(27.7)$ & $57(36.8)$ & & \\
Working status & Teachers & $1(0.6)$ & $4(2.3)$ & & \\
$\mathrm{N}(\%)$ & Non-occupied & $8(4.6)$ & $13(8.4)$ & $\chi_{(1)}^{2}=26.4$ & \\
Education & Occupied & $1(0.6)$ & $1(0.6)$ & & \\
$\mathrm{N}(\%)$ & $<=8$ years & $6(3.9)$ & $11(6.4)$ & $\chi_{(2)}^{2}=1.17$ & \\
& $<=13$ years & $7(4.0)$ & $16(10.3)$ & & \\
Marital status & <= 18 years & $74(47.7)$ & $84(48.6)$ & & \\
$\mathrm{N}(\%)$ & Unmarried & $4(2.3)$ & $1(0.6)$ & $\chi_{(1)}^{2}=1.70$ & 0.19 \\
\hline & Married & $62(43.4)$ & $58(36.0)$ & & \\
\hline
\end{tabular}


validity of the questionnaire, the authors found positive and low to moderate correlations between BFW and Extraversion (Pearson's $r=.20)$ and Agreeableness $(r=.19)$, whereas the correlation between BFW and Neuroticism was close to zero but negative $(r=-.07)$. On the other hand, they also found that BFD correlated positively with Agreeableness $(r=.19)$ and negatively with Emotional Stability $(r=-.22)$.

The Zuckerman-Kuhlman-Aluja Personality Questionnaire (ZKA-PQ; Aluja et al., 2010) is a 200-item questionnaire based on the theoretical constructs of the alternative five-factormodel of personality. Participants are asked to express their degree of agreement with respect to a set of statements that describe several ways in which people may act and think. The five factors and their relevant facets, are, respectively: (i) Activity (Work Compulsion, e.g., "My work is my primary pleasure in life."; General Activity, e.g., "I do not like to waste time just sitting down and relaxing."; Restlessness, e.g., "I cannot sit down or remain in the same position for long."; Work Energy, e.g., "When I work, I really exert myself to the fullest."), (ii) Aggressiveness (Physical Aggression, e.g., "If somebody hits me, I hit them back."; Verbal Aggression, e.g., "When people annoy me, I tell them what I think of them."; Anger, e.g., "When I feel frustrated, I usually show my annoyance."; Hostility, e.g., "I cannot help being rude to people I do not like."), (iii) Extraversion (Positive Emotions, e.g., "I am usually happy."; Social Warmth, e.g., "Others think that I am an affectionate person."; Exhibitionism, e.g., "I like to be the center of attention in a gathering."; Sociability, e.g., "I like working as part of a team."), (iv) Neuroticism (Anxiety, e.g., "Often I feel uneasy."; Depression, e.g., "Negative thoughts sometimes obsess me."; Dependency, e.g., "I feel helpless if there is no one to advise me."; Low Self-Esteem, e.g., "I am not very confident about myself or my abilities."), and (v) Sensation Seeking (Thrill Adventure Seeking, e.g., "I enjoy the sensations of speeding in a car."; Experience Seeking, e.g., "I enjoy getting into new situations where you can't predict how things will turn out."; Disinhibition, e.g., "I do not try to restrain my urges to have exciting experiences."; Boredom Susceptibility and Impulsivity, e.g., "I prefer friends who are excitingly unpredictable."). The model aimed to improve the Big-Five model of personality, based on an evolutionary theoretical basis. The two models share similarities. For example, Aluja et al. (2002) showed that Extraversion-Sociability and Neuroticism-Anxiety from the ZKA-PQ highly correlated with the NEO-PI versions of Extraversion $(r=.66)$ and Neuroticism $(r=.81)$, whereas Aggressiveness-Hostility from the ZKA-PQ negatively correlated with the NEO-PI version of Agreeableness $(r=-.59)$. Moreover, Activity highly correlated with the NEO-PI version of Extraversion $(r=.38)$. Total ZKA-PQ scores are obtained by summing up items loading onto their relevant factor. Higher scores in each scale indicate higher levels of the relevant personality trait. Research showed that the Italian version of the scale is reliable (Cronbach's alpha values for the five factors, respectively: Aggressiveness $=.83$, Activity $=.71$, Extraversion $=.77$, Neuroticism $=.81$, Sensation seeking $=$ .74) (Iliceto et al., 2016). Regarding the criterion-related validity of the ZKA-PQ, Fino et al. (2014) showed that Activity, Extraversion, and Sensation Seeking correlated positively with Self- $(r=.32, .33$, and .24$)$ and Other-Representations $(r=.31$, .30 , and .22) of adult attachment. In the current study, we found that all the scales were reliable, respectively showing the following values of Omega $(95 \% \mathrm{CI})$ : Aggressiveness $=.80(.74-.86)$, Activity $=.82(.76-.87)$, Extraversion $=.81(.76-.87)$, Neuroticism $=.72(.64-.79)$, and Sensation Seeking $=.81$ (.75-.86).

The 9 Attachment Profile (9AP: Candilera, 2007) is a semiprojective test, assessing the quality of interpersonal relationships. It is based on Bowlby's (1969) attachment theoretical framework, relating to Self-and Other-Representations as internal working models of adult attachment. The 9AP measures one's set of representations and expectations in relation to the self and to significant others, along two opposite orientations (positive vs. negative). The test includes a set of basic pictures displaying some interaction of black and white silhouettes, with each picture being accompanied by a pair of semantically contrasting terms. Two items ask participants to rate their perception of themselves and of the others, respectively, using a 9-point Likert-type scale, with lower scores indicating endorsement of the first term and higher scores indicating endorsement of the second term. In total, the 9AP includes nine pairs of items, relevant to the following terms: (i) acceptancerejection, (ii) friendliness-hostility, (iii) power-submission, (iv) security-insecurity, (v) availability-unavailability, (vi) calm-agitation, (vii) satisfaction-dissatisfaction, (viii) independence-dependence, and (ix) competitiveness-uncompetitiveness. Figure 1 illustrates one of the pictures used in the scale and the associated terms and items, translated from the original Italian version.

9AP total scores are obtained by adding up the scores of the 9 self-related items and the scores of the 9 other-related items, summarizing the two dimensions of Self-Representations and Other-Representations, with higher scores indicating an overall positive perception of oneself and an overall positive perception of others, respectively. Values of Omega $(95 \% \mathrm{CI})$ estimated in the current study were: Self $=.83(.78-.88)$, and Other $=.80(.73-.86)$.

\section{Statistical Analyses}

We used two-tailed $t$-tests and Pearson's correlation coefficients, and $\chi^{2}$ tests with Yates's correction where appropriate. We examined and evaluated the use of the FAD-Plus-I response categories in the current sample, aiming to investigate any possible floor and ceiling effects. We considered a response frequency $\geq 15 \%$ on the lowest and highest item response categories (1/5 and 5/5) as indicative of floor and 
Fig. 19 Attachment Profile (9AP): Exemplificative item (translated from the original Italian version)

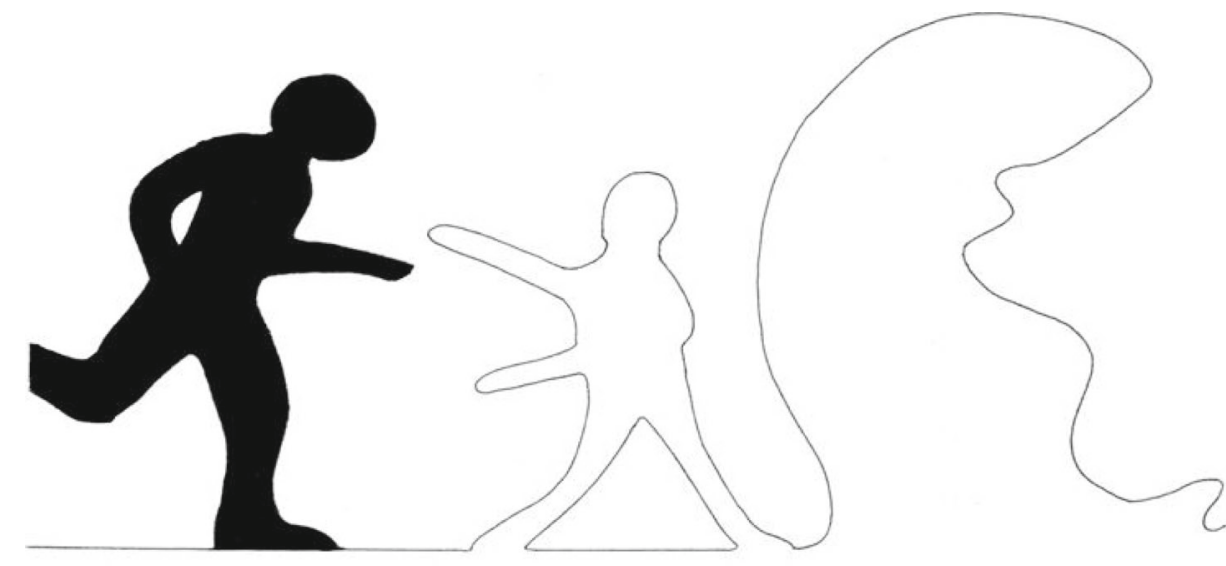

If you were the one represented as the black silhouette:

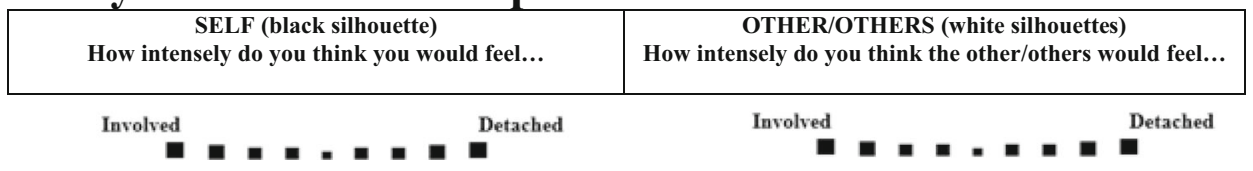

ceiling effects, respectively (McHorney \& Tarlov, 1995; Petrillo et al., 2015). We also estimated the skewness and kurtosis statistics on all the items, expecting values to be comprised approximately between -2 and 2 . We detected multivariate outliers by computing generalized Cook's Distances (gCDs)(Chalmers \& Flora, 2015; Pek \& McCallum, 2011), measuring the influence of an observation on parameters estimated from the four-factor analytic model accounting for the FAD-Plus-I hypothesized factors. We used the percentile on the $F$ distribution (with $k+1, n-k$ - 1 , whereas $k$ represents the number of variables and $n$ represents the number of observations in the data) as the cut-off criterion, an and we proceeded by removing the observations showing a distance greater than the estimated cut-off.

We used two alternative approaches to investigate the factor structure and construct validity of the FAD-Plus-I: (i) Exploratory Structural Equation Modelling (ESEM), and (ii) Confirmatory Factor Analysis (CFA). We split the overall dataset in two randomly generated and approximately equally sized datasets, and we used the first dataset to test the theoretical model of the FAD-Plus-I via ESEM and CFA, and the second dataset to cross-validate the results by means of gender invariance testing and to examine the criterion-related validity of the measure.

ESEM is a technique that incorporates the advantages of exploratory and confirmatory factor analysis techniques (Tóth-Király, 2017). It enables a researcher to fit a less restrictive model compared to a confirmatory model, leaving items free to cross-load on multiple latent factors, ultimately providing a solid framework for the evaluation of the model's fit to the data (Asparouhov\& Muthén, 2009; Marshet al., 2014). We implemented ESEM by means of a two-step approach: (i) we ran two independent exploratory factor analyses on two groups of variables (first group = items hypothesized to load onto BFD and BUP; second group = items hypothesized to load onto BFW and BSD) and extended them into each other, as described by Revelle (2020); (ii) we combined the factor loadings and the covariance matrices from the two analyses into a structural model in which all the items were left free to cross-load, although directed to load onto their hypothesized substantive factors. We used geomin rotation to account for the hypothesized correlations between BFD and BSD, and between BFD and BUP, and the Unweighted Least Squares (ULS) estimator. ULS has several advantages with categorical and ordinal data, including a more accurate estimation of parameters and standard errors, a better performance in relatively small samples and in data displaying floor and ceiling effects (Muthén et al., 2015). Moreover, ULS makes no distributional assumptions (Flora \& Curran, 2005; Li, 2016). CFA is a technique used to test a set of hypotheses on the relations between observed variables and their underlying latent constructs, and it is commonly used in scale validation studies. CFA implies the formal specification of the measurement instrument in terms of a factor model, the statistical fitting of the factor model to the observed data, the assessment of model's fit, and the interpretation of the model consistently with the data. The following criteria were used to evaluate the goodness of each of the models' fit: The Comparative Fit Index $(\mathrm{CFI}) \geq 0.950$, the Root Mean Square Error of Approximation (RMSEA) with the top of the $90 \%$ confidence interval $\leq 0.07$, and the Standardized Root Mean Square Residual $($ SRMR) $\leq 0.08$ (Kenny, 2015).

We used structural equation modelling (SEM) to detect and to control for common method bias. Common method bias is 
defined as a form of common variance deriving from a series of possible sources of influence that are extraneous to the intended constructs in the measurement model (Podsakoff et al., 2003). Edwards (2008) classified such sources as "response tendencies that raters apply across measures, similarities in item structure or wording that induce similar responses, the proximity of items in an instrument, and similarities in the medium, timing, or location in which measures are collected" (p. 476). Common method bias can have a detrimental effect on the validity and the reliability of a measure and can influence the covariation between latent dimensions (Baumgartner \& Steenkamp, 2001). For this reason, we proposed and tested a bifactor model by means of ESEM, consisting of four substantive factors and a common method bifactor loaded by all the FAD-Plus-Iitems, and we compared the fit of the model to the fit of the baseline model tested by means of ESEM. Regarding CFA, we also added a first-order additional factor to the CFA model, with the items left free to load onto their relevant factors and constrained to equally load onto the additional method factor (Podsakoff et al., 2012). This technique allows a researcher to detect possible common method bias post-hoc and "it models the effect of the method factor at the measurement level, rather than at the latent construct level"' (p. 553).

We measured the reliability of the FAD-Plus-I factors by means of coefficient Omega (Green \& Yang, 2009). Specifically, we analysed the reliability of each of the four FAD-Plus-I scales by using the observed covariance matrix to compute the total variance. We estimated the $95 \%$ confidence intervals by using the adjusted bootstrap percentile method (1999 repetitions). Values $\geq 0.80$ were considered as indicative of satisfactory reliability. The construct validity of the FAD-Plus-I was further assessed by testing for its gender invariance. We estimated a series of nested structural models aimed to investigate whether the measurement properties of the FAD-Plus-I were invariant across female respondents and male respondents. Following recommendations for multigroup analyses with ordinal data (Svetinaet al., 2019), we ran and compared a series of progressively more restrictive models, in the following order: (i) aconfigural model (ii) a model in which item thresholds were constrained to be equal across groups (iii) a model in which factor loadings were constrained to be equal across groups. Considering the relatively low sample size obtained in the current study, we decided not to test for more restrictive models. The following criteria (Chen, 2007; Cheung and Rensvold, 2002; Putnick \& Bornstein, 2016) were used to compare the models' fit: -0.010 change in CFI $(\Delta C F I)$ combined with 0.015 change in RMSEA ( $\triangle$ RMSEA) and 0.015 change in SRMR ( $\triangle \mathrm{SRMR})$. We finally estimated the coefficient of congruence between the factor loadings from the retained structural model and the factor loadings reported in Paulhus and Carey's (2011) proposed model, considering values $\geq .60$ as indicative of similarity between the two matrices.

Finally, we used the second dataset to perform a correlation analysis aimed at examining the criterion-related (concurrent) validity of the FAD-Plus-I, using Spearman's $r_{s}$ correlation coefficient. We estimated the correlations between the FAD-Plus-I items and the external variables, namely the five ZKA-PQ factors (Aluja et al., 2010) and the 9AP Self-and Other-Representations dimensions (Candilera, 2007). We controlled for the possible effects of sex and age by means of partial correlations between the FAD-Plus-I items and the external variables in a monotonic relationship analysis.

All analyses were performed by using the statistical programming language $\mathrm{R}$ (Version 3.6.2), including the following packages: R Base (RCore Team, 2019), lavaan (Rosseel, 2012) psych (Revelle, 2020), and semTools (Jorgensenet al., 2019).

\section{Results}

\section{Preliminary Data Screening}

We screened the data for missing information and unengaged response patterns $(S D<0.30)$ across all the FAD-Plus-I items. We found no missing data nor unengaged response patterns, and for this reason, we retained the 328 observations from the original dataset. We identified 51 observations as being outside the expected range for multivariate normality indicated by the estimated gCDs, and for this reason, we decided to remove them from the final dataset, retaining a total of 277 observations. Subsequently, we evaluated the use of the FAD-Plus-I items' response options. We found several items presenting a proportion of responses in extreme categories that fell outside the acceptable ranges. However, the observed values of skewness and kurtosis were all comprised approximately between -1 and 1 . Table 2 presents the detailed frequencies by response options, along with the skewness and kurtosis statistics. Based on such evidence, we decided to retain the original 5-point response scale for all the items, with no modifications.

\section{Exploratory and Confirmatory Structural Equation Modelling}

ESEM and CFA were run on the first randomly generated dataset $(n=139)$. We fitted and evaluated two alternative baseline models: An ESEM model with geomin rotation (Model 1) and a CFA model (Model 2). Results showed that both the ESEM (CFI $=0.942$, RMSEA $=0.119[90 \% \mathrm{CI}=$ $0.110-0.128], \mathrm{SRMR}=0.135)$, and the CFA $(\mathrm{CFI}=0.943$, 
Table 2 Analysis of item response categories, skewness and kurtosis $(N=277)$

\begin{tabular}{|c|c|c|c|c|c|c|c|}
\hline Item & 1 & 2 & 3 & 4 & 5 & Skewness & Kurtosis \\
\hline 1. I believe that the future has already been determined by fate. & 1.08 & 6.50 & 31.41 & 41.88 & 19.13 & -0.35 & -0.12 \\
\hline 2. People's biological makeup determines their talents and personality. & 4.33 & 15.16 & 24.55 & 30.69 & 25.27 & -0.41 & -0.73 \\
\hline 3. Chance events seem to be the major cause of human history. & 3.61 & 13.72 & 27.08 & 33.21 & 22.38 & -0.40 & -0.58 \\
\hline 4. People have complete control over the decisions they make. & 3.61 & 11.91 & 28.88 & 23.10 & 32.49 & -0.42 & -0.77 \\
\hline 5. No matter how hard you try, you can't change your destiny. & 0.72 & 7.94 & 29.24 & 40.07 & 22.02 & -0.34 & -0.42 \\
\hline 6. Psychologists and psychiatrists will eventually figure out all human behavior. & 1.08 & 7.58 & 31.77 & 38.99 & 20.58 & -0.32 & -0.31 \\
\hline 7. No one can predict what will happen in this world. & 4.69 & 12.64 & 27.08 & 32.49 & 23.10 & -0.45 & -0.53 \\
\hline 8. People must take full responsibility for any bad choices they make. & 15.52 & 28.88 & 23.10 & 25.63 & 6.86 & 0.09 & -1.01 \\
\hline 9. Fate already has a plan for everyone. & 7.94 & 31.05 & 42.24 & 18.05 & 0.72 & -0.09 & -0.48 \\
\hline 10. Your genes determine your future. & 4.33 & 16.25 & 25.99 & 29.24 & 24.19 & -0.34 & -0.80 \\
\hline 11. Life seems unpredictable - just like throwing dice or flipping a coin. & 0.72 & 43.68 & 32.85 & 22.38 & 0.36 & 0.38 & -1.09 \\
\hline 12. People can overcome any obstacles if they truly want to. & 8.66 & 27.80 & 37.55 & 22.02 & 3.97 & 0.02 & -0.51 \\
\hline 13. Whatever will be, will be - there's not much you can do about it. & 9.03 & 28.88 & 40.43 & 18.77 & 2.89 & 0.03 & -0.39 \\
\hline $\begin{array}{l}\text { 14. Science has shown how your past environment created your current intelligence and } \\
\text { personality. }\end{array}$ & 0.00 & 9.03 & 32.13 & 38.27 & 20.58 & -0.14 & -0.78 \\
\hline 15. People are unpredictable. & 3.97 & 13.00 & 27.44 & 32.13 & 23.47 & -0.42 & -0.57 \\
\hline 16. Criminals are totally responsible for the bad things they do. & 6.86 & 29.96 & 40.43 & 18.05 & 4.69 & 0.18 & -0.28 \\
\hline 17. Whether people like it or not, mysterious forces seem to move their lives. & 9.03 & 29.60 & 38.27 & 20.22 & 2.89 & 0.03 & -0.48 \\
\hline 18. As with other animals, human behavior always follows the laws of nature. & 1.08 & 7.58 & 32.13 & 38.63 & 20.58 & -0.31 & -0.33 \\
\hline 19. Life is hard to predict because it is almost totally random. & 3.97 & 13.72 & 27.08 & 32.49 & 22.74 & -0.40 & -0.60 \\
\hline 20. Luck plays a big role in people's lives. & 5.05 & 12.27 & 26.71 & 32.13 & 23.83 & -0.47 & -0.52 \\
\hline 21. People have complete free will. & 15.16 & 28.16 & 23.83 & 26.35 & 6.50 & 0.05 & -1.00 \\
\hline 22. Parents' character will determine the character of their children. & 3.97 & 15.88 & 26.71 & 29.24 & 24.19 & -0.33 & -0.78 \\
\hline 23. People are always at fault for their bad behavior. & 9.39 & 28.52 & 36.10 & 22.02 & 3.97 & 0.03 & -0.57 \\
\hline 24. Childhood environment will determine your success as an adult. & 0.36 & 8.30 & 32.49 & 38.99 & 19.86 & -0.19 & -0.58 \\
\hline 25. What happens to people is a matter of chance. & 0.36 & 44.77 & 32.13 & 22.02 & 0.72 & 0.46 & -1.03 \\
\hline 26. Strength of mind can always overcome the body's desires. & 7.22 & 29.96 & 38.99 & 19.49 & 4.33 & 0.14 & -0.37 \\
\hline 27. People's futures cannot be predicted. & 5.05 & 12.27 & 27.44 & 32.13 & 23.10 & -0.46 & -0.51 \\
\hline
\end{tabular}

RMSEA $=0.117$ [90\% CI $=0.108-0.126]$, SRMR $=0.134$ ) had unsatisfactory fit to the data.

We further examined those baseline models by introducing the analysis of common method bias. We fitted the proposed bifactor model by means of ESEM, accounting for an additional common method factor loaded by all the items (Model 3), and a CFA model with all the items loading not only onto their relevant factors but also onto one orthogonal method factor (Model 4). Both models showed an improvement compared to their baseline counterparts $($ Model 3: CFI $=1.000$, RMSEA $=0.000[90 \%$ $\mathrm{CI}=0.000-0.000], \mathrm{SRMR}=0.045)$, Model 4: $\mathrm{CFI}=$ 0.963, RMSEA $=0.095$ [90\% CI $=0.085-0.104$ ], SRMR = 0.117). The bifactor model was retained as the best to represent the data. The coefficient of congruence estimated between the factor loadings from the bifactor model and Paulhus and Carey's (2011) solution presented a value equal to .95 , confirming the congruence of the factors derived in the present study to the original solution. Table 3 presents factor loadings and covariances from the bifactor model.

\section{Reliability}

We found that all the scales were reliable, with Omega values $(95 \% \mathrm{CI})$ being, respectively: $\mathrm{FW}=.95(.94-.96)$, $\mathrm{FD}=0.91(.81-.93), \mathrm{SD}=0.94(.92-.96)$, and $\mathrm{UP}=.98$ (.97-.99).

\section{Measurement Invariance}

We estimated, evaluated, and compared three models to test for the gender (female respondents, male respondents) invariance of the FAD-Plus-I: (i) a configural model; (ii) a model in which item thresholds were constrained to be equal across the two groups; (iii) a model in which factor loadings were constrained to be equal across the two groups. We conducted the analysis on the second dataset 
Table 3 Standardized factor loadings and covariances (ESEM bifactor model; the metric of each latent variable was determined by fixing their residual variances to 1.0)
Factor loadings

$\begin{array}{lc}\text { First set } & \text { Fatalistic Determinism } \\ \text { Item } 25 & -0.10 \\ \text { Item } 3 & 0.02 \\ \text { Item } 20 & 0.01 \\ \text { Item } 19 & -0.03 \\ \text { Item } 11 & -0.06 \\ \text { Item 7 } & 0.05 \\ \text { Item 15 } & 0.05 \\ \text { Item 27 } & 0.05 \\ \text { Item 9 } & 0.40 \\ \text { Item 1 } & 0.41 \\ \text { Item 13 } & 0.98 \\ \text { Item 17 } & 0.98 \\ \text { Item 5 } & 0.98\end{array}$

Free Will

Second set

Item 6

Item 14

Item 18

Item 24

Item 2

Item 10

Item 22

Item 4

Item 8

Item 12

Item 23

Item 21

Item 16

Item 26

Factor covariances

1. Fatalistic Determinism

2. Unpredictability

3. Free Will

0.66

0.62

0.09

4. Scientific Determinism

$\begin{array}{cc}\text { Unpredictability } & \text { General } \\ 0.99 & -0.04 \\ 0.98 & 0.00 \\ 0.98 & -0.02 \\ 0.98 & 0.02 \\ 0.98 & -0.02 \\ 0.97 & -0.03 \\ 0.96 & -0.04 \\ 0.87 & 0.01 \\ 0.44 & -0.08 \\ 0.43 & -0.09 \\ -0.03 & 0.05 \\ -0.04 & 0.03 \\ -0.06 & 0.06\end{array}$

Scientific Determinism

General

0.96

$-0.17$

$-0.16$

$-0.18$

$-0.20$

$-0.27$

$-0.24$

$-0.26$

0.77

0.78

0.65

0.65

0.79

0.73

0.65
2

3

0.48

0.06
( $n=138)$, and results from ESEM showed that invariance was established at the level of thresholds and loadings, with no significant decrease in the fit indices across the nested models. Conversely, results from CFA showed a non-satisfactoryfit across the three models. The detailed results from the analysis are reported in Table 4.

\section{Criterion-Related Concurrent Validity}

We used the second dataset also to explore factor intercorrelations and correlations between the four FAD-Plus-I factors and the external variables. Regarding the factor inter-correlations, BFD and BUP were positively and highly correlated $\left(r_{s}\right.$ 
Table 4 FAD-Plus-I Gender Invariance Analysis $(n=138)$

\begin{tabular}{lcccccccccc}
\hline \multicolumn{1}{c}{ ESEM } & \multicolumn{10}{c}{ CFA } \\
\hline Model & CFI & RMSEA & \multicolumn{1}{c}{ RMSEA 90\% CI } & SRMR & CFI & RMSEA & \multicolumn{2}{c}{ RMSEA 90\% CI } \\
& & & Lower & Upper & & & Sower & Upper \\
Configural & 1.000 & 0.000 & 0.000 & 0.000 & 0.064 & 0.955 & 0.105 & 0.095 & 0.115 & 0.146 \\
Thresholds & 1.000 & 0.000 & 0.000 & 0.000 & 0.064 & 0.953 & 0.103 & 0.093 & 0.113 & 0.146 \\
Loadings & 1.000 & 0.000 & 0.000 & 0.000 & 0.079 & 0.952 & 0.103 & 0.093 & 0.112 & 0.148 \\
\hline
\end{tabular}

$=.66, p<.001)$, whereas all the other factors showed positive low to moderate correlations (values ranging from 0 to .24).

BFW correlated positively and lowly to moderately with Aggressiveness $\left(r_{s}=.12, p=.173\right)$, Activity $\left(r_{s}=.27, p=\right.$ $.001)$, Extraversion $\left(r_{s}=.25, p<.005\right)$, Self- $\left(r_{s}=.40, p<\right.$ $.001)$ and Other-Representations $\left(r_{s}=.43, p<.001\right)$, whereas its correlations with Neuroticism $\left(r_{s}=.04\right)$ and Sensation Seeking $\left(r_{s}=-.01\right)$ were close to zero. BFD correlated positively and lowly with Other-Representations $\left(r_{s}=.11, p=\right.$ .200) and negatively with Sensation Seeking $\left(r_{s}=-.12, p=\right.$ .156), with the other set of correlation showing values close to zero (values ranging from -.01 to .03). BSD correlated positively and moderately with Activity $\left(r_{s}=.31, p<.001\right)$, Extraversion $\left(r_{s}=.44, p<.001\right)$, Self- $\left(r_{s}=.52, p<.001\right)$ and Other-Representations $\left(r_{s}=.48, p<.001\right)$, whereas its correlations with Aggressiveness Neuroticism, and Sensation Seeking were close to zero (values ranging from .01 to .08). BUP correlated positively and lowly with Aggressiveness $\left(r_{s}\right.$ $=.16, p=.053)$ and negatively with Sensation-Seeking $\left(r_{s}=\right.$ $-.12, p=.171)$. All the other correlations between BUP and the external variables showed values that were close to zero (values ranging from -.05 to .07).

Table 5 presents the complete results from the correlation analysis between the FAD-Plus-I factors and the external variables. Appendix Table 6 includes the results from the detailed monotonic relationship analysis between the FAD-Plus items and the external variables, controlled by gender and age, showing no substantial change in the correlations as a function of the two variables.

\section{Discussion}

The current study had four aims: First, to test the factor structure and the measurement model of the Italian translation of the FAD-Plus (FAD-Plus-I) in a sample of adults from the Italian community. Second, to test the reliability of the four scales, measuring beliefs in free will, fatalistic determinism, scientific determinism, and unpredictability, respectively. Third, to test whether the FAD-Plus-I is gender invariant. Fourth, to analyze the criterion-related (concurrent) validity of the measure. We used ESEM and CFA to test the factor structure of the FAD-Plus-I, fitting two baseline models and two models accounting for an orthogonal "general" factor (bifactor model through ESEM, common method model factor through CFA, respectively). The results showed that the bifactor model was the best to represent the data, displaying adequate fit and revealing superior to both the baseline models and the common method factor model fitted through CFA, ultimately confirming the factor structure identified by Paulhus and Carey (2011) and our original hypothesis (H1). In the same vein, the coefficient of congruence computed between the factor loadings obtained from the proposed bifactor model and the factor loadings derived from Paulhus
Table 5 Criterion-Related Validity Analyses $(n=138)$

\begin{tabular}{llllc}
\hline Measures & Free Will & $\begin{array}{l}\text { Fatalistic } \\
\text { Determinism }\end{array}$ & $\begin{array}{l}\text { Scientific } \\
\text { Determinism }\end{array}$ & Unpredictability \\
\hline Aggressiveness (ZKA-PQ) & 0.12 & 0.02 & 0.08 & 0.16 \\
Activity (ZKA-PQ) & $0.27^{* * *}$ & 0.03 & $0.31^{* * *}$ & 0.00 \\
Extraversion (ZKA-PQ) & $0.25^{* *}$ & -0.01 & $0.44^{* * *}$ & -0.05 \\
Neuroticism (ZKA-PQ) & 0.04 & -0.01 & 0.01 & 0.07 \\
Sensation-Seeking & -0.01 & -0.12 & 0.02 & -0.12 \\
$\quad$ (ZKA-PQ) & & & $0.52^{* * *}$ & 0.02 \\
Self-Representations (9AP) & $0.40^{* * *}$ & 0.03 & $0.48^{* * *}$ & 0.02 \\
Other-Representations & $0.43^{* * *}$ & 0.11 & & \\
$\quad$ (9AP) & & & & \\
\hline
\end{tabular}

Note. $* * *$ indicates $p<.001 ; * *$ indicates $p<.01$ 
and Carey's (2011) original study supported the suitability of the empirical factor solution to the original theoretical model. All the scales were reliable, showing satisfactory levels of Omega (H2). The model was gender invariant at the level of item thresholds and factor loadings, thus confirming our hypothesis (H3).

An important aspect emerging from the present study was the detection of common latent variance in the FADPlus-I measurement model. As noted by Podsakoff et al. (2012), method bias can represent a significant source of bias in all those cases when individuals are not able to provide accurate responses as a function of either their ability or their motivation to respond. Although the present study could not identify any specific source of bias, we found that the structural models accounting for a general "method" factor improved the fit of the model to the data, both in the case of ESEM and of CFA. These results indicate that systematic bias might affect the measurement and remedies are required. Although statistical modelling allowed us to control for possible method bias, it is of foremost importance for future research to clarify the extent to which such relations affect the reliability and the validity of the FAD-Plus-I, ideally by implementing a priori procedural methods to control for the possible sources of method bias.

Another important outcome of the present study is that the proposed bifactor model was gender invariant at the level of item thresholds and factor loadings. It must be noted that we did not test for intercepts nor residual invariance due to the relatively small sample size used in the current study. Future research will need to use larger and more representative samples to address the question as to whether the FAD-Plus-I is gender invariant in intercepts and residuals, further analyzing latent mean and latent variance structures.

Regarding the criterion-related concurrent validity of the FAD-Plus-I, we found that BFW correlated positively with Extraversion (H4a) and with Self- (H4b) and OtherRepresentations of adult attachment ( $\mathrm{H} 4 \mathrm{c}$ ), thus confirming the relevant hypotheses. However, BFW correlated positively with Aggressiveness, too (H4d), contrary to our initial hypothesis. The correlation between BFD and Other Representations ( $\mathrm{H} 4 \mathrm{~g})$ was positive and low, confirming our hypotheses, although the correlations of BFD with Neuroticism (H4e), Aggressiveness (H4h), and Self-Representations (H4f)were close to zero, thus not confirming our hypotheses. These results are, to a certain extent, consistent with the results presented by Paulhus and Carey, who found that the BFW scale was positively correlated with Agreeableness and with Extraversion, in line with the hypothesis that BFW are associated with prosocial behavior and an individual's sense of autonomy, although not highly. Interestingly, we also found a positive correlation between the alternative personality factor of Activity and BFW, potentially suggesting a relation between work compulsion, general activity, restlessness, work energy, and BFW. Furthermore, BFD showed low correlations with all the five personality factors, and the low correlations between BFD and Neuroticism may suggest that individuals with higher emotional stability tend to belief that one's future is not determined by external forces, as already discussed in the original validation study of the FAD-Plus (Paulhus \& Carey, 2011).

Additionally, we found positive and moderate correlations between beliefs in BFW and Self-and OtherRepresentations of adult attachment, contributing to support the general assumption that a prosocial orientation and interpersonal security are associated to beliefs in individuals' autonomy (Paulhus \& Carey, 2011; see also Iliceto et al., 2020). On the other hand, we found low correlations between beliefs in BFD and Self-and Other-Representations. Although apparently counter-intuitive, these results are consistent with findings from recent literature. In this regard, Boudesseul et al. (2016) argued that depending on the contexts or experience, $\mathrm{BFW}$ may relate to aspects of a relationships that pertain to values of autonomy and freedom in relationships, whereas, on the contrary, believing in determinism may refer to aspects such as the perception of not being fully in control of one's own decisions and actions, possibly indicating individual differences in internal working model of attachment. However, despite the interesting results, any further speculations are beyond the scope of the current study, and we invite researchers to take the opportunity to investigate such hypotheses in a more in-depth manner in future research.

Another novel finding observed in our study is represented by the gender invariant psychometric properties of the FAD-Plus-I. Paulhus and Carey (2011) found gender differences in BSD beliefs, with women scoring significantly lower than men in both the undergraduate samples and the community sample, and women scoring significantly higher in BFW in the community sample. The results from the current study may reflect essential cultural differences in the belief in the role of scientific causality in addressing an individual's choices and actions. Interestingly, this was a limitation highlighted by Paulhus and Carey (2011), in the first place. In fact, they recognized that "the worldviews implicated in research on free will and related constructs will differ across cultures" (p. 103). With specific regards to the Italian context, we envisage a role for several possibly moderating variables, such as religious views, level of diffusion of scientific knowledge, common understanding of scientific causality and related processes, perception of the impact of biological factors on people's personality and behavior, logical thinking, and further ethical and moral values embedded and widespread in the community (see Crivellaro \& Sperduti, 2014). We suggest future research in the Italian context to clarify the role of such variables in relation to $\mathrm{BSD}$. 


\section{Limitations}

This study has some limitations. First and of foremost importance, the small size of the sample might have affected the stability of the estimates of ESEM and CFA models, and for this reason, the results from the present study cannot be considered as definitive. We recommend future research to investigate the psychometric properties and measurement invariance of the FAD-Plus-I in larger samples, considering and controlling for possible sources of common method bias using a priori procedures, aiming to eliminate common scale properties, and possibly examine the effect of a temporal delay in the administration of different scales. Second, the sample used in the current study did not allow to generalize results to the entire population, nor did we ask questions on sexual orientation and gender identity, requiring further investigation of the reliability and validity of the scale in larger and representative samples. Third, we did not perform cognitive interviewing, nor did we assess the quality of the overall survey before its administration. Fourth, test-retest reliability was not investigated. Fifth, the correlations found between the FAD-Plus factors and the alternative personality factor model warrant further research, possibly aiming to test the criterion-related validity of the FAD-Plus in relation to other personality models.

\section{Implications}

We believe that the results from the current study have at least four theoretical implications: First, they provide support to the theoretical model of BFW and beliefs in determinism as coexisting and measurable dimensions. Second, they indicate that beliefs in determinism underly two distinct dimensions, namely BFD and BSD. In fact, on the one hand, BFD indicates beliefs that fate rules over individuals' lives, restricting their potential to act and power to make decisions, and on the other hand, BSD refers to believing that "environments can be manipulated to improve society with no implication of inevitability" (Paulhus \& Carey, 2011, p. 103). Third, our results confirm the internal consistency and construct validity of a fourth factor, namely BUP, representing beliefs in randomness, luck, and unpredictability, thus supporting the overall construct validity of the multifactorial theoretical and measurement model proposed by Paulhus and Carey (2011). Fourth, the results confirmed the reliability and the criterionrelated validity of the FAD-Plus measurement model in a different cultural context compared to the one in which it had been originally designed and developed, providing evidence on its cross-cultural validity and its adaptability to the Italian community.

Furthermore, we foresee several applications for the FADPlus-I in the community. Specifically, individuals who believe in free will are more likely to hold healthy relationships with themselves and the others, and as argued by Feltz (2015), and believing in free will may be "necessary for autonomy, creativity, desert, reactive attitudes, dignity, love, and friendship" (p. 113), even be required to avoid interpersonal conflicts (Kane, 1996). For this reason, effective prevention and intervention strategies in the social context may benefit from considering the assessment of BFW, BFD, BSD, and BUP by means of the FAD-Plus-I, providing researchers and practitioners with a reliable and valid screening tool to assess and potentially support those at higher risk for displaying dysfunctional patterns of interpersonal relationships. In fact, a timely assessment could help preventing individuals who believe that they have little or no power over the course of their actions from behaving irresponsibly, aggressively, and anti-socially (Baumeister \& Monroe, 2014), with positive impact on their physical and mental health and on the overall community. Additionally, because previous studies found that BFW is associated with an internal locus of control (Paulhus \& Carey, 2011), higher performance at work, and a tendency to refrain from cheating (Baumeister et al., 2009, Baumeister et al., 2008), the results from the current study will allow researchers and practitioners in psychology in the Italian context to use a reliable and valid assessment in academic, occupational, and legal settings, ultimately enabling them to design and implement effective assessment and resource management policies in those areas. Last, a recent research by $\mathrm{Fu}$ et al. (2021) has identified a pattern of relationship between beliefs in determinism and risk for developing depression, supporting a role for such beliefs in decreasing self-control and resilience. Thus, the FAD-Plus-I will represent a useful resource in clinical settings such as counseling and psychotherapy, as well, although more research in this area is warranted.

\section{Conclusions}

In summary, the results from the current study confirm that the FAD-Plus-I can be successfully adapted to the cultural and linguistic Italian context, underlying a four-factor structure of BFW, $\mathrm{BFD}, \mathrm{BSD}$, and BUP, and showing gender invariant properties. From a conceptual point of view, our results contribute to support Paulhus and Carey's (2011) conceptualisation of BFW and beliefs in determinism, considered as independent constructs rather than contrasting poles of the same dimension. Finally, we found preliminary evidence on the reliability, construct, and criterionrelated validity of the FAD-Plus-I, although the limitations of the study require caution in their interpretation.

Authors' Contributions All authors equally contributed to the study conception, design, material preparation, data collection and analysis, writing and revision of all the versions of the manuscript. All authors read and approved the final version of the manuscript. 


\section{Appendix}

\section{English version and Italian version of the FAD-Plus}

For each statement below, choose a number from 1 to 5 to indicate how much you agree or disagree.

Per ciascuna delle seguenti affermazioni, scelga un numero da 1 a 5 per indicare quanto è d'accordo o in disaccordo.
$+1$
$+2$
$+3$
$+4$
$+5$

Strongly Disagree

Strongly Agree

Fortemente in disaccordo

Fortemente d'accordo

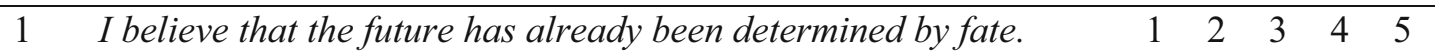

Credo che il futuro sia già stato determinato dal destino.

2 People's biological makeup determines their talents and $\quad \begin{array}{llllll}1 & 2 & 3 & 4 & 5\end{array}$ personality.

Il DNA delle persone determina il loro talento e la loro personalità.

3 Chance events seem to be the major cause of human history. $\quad \begin{array}{lllll}1 & 2 & 3 & 4 & 5\end{array}$

Gli eventi del caso sembrano essere la causa principale della storia umana.

$4 \quad$ People have complete control over the decisions they make. $\quad$\begin{tabular}{lllll}
\hline 4 & 2 & 3 & 4 & 5
\end{tabular}

Le persone hanno il controllo totale sulle decisioni che prendono.

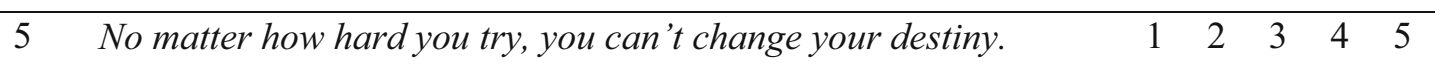

Non importa quanto ci provi, non puoi cambiare il tuo destino.

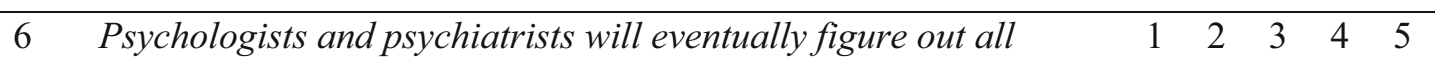
human behavior.

Psicologi e psichiatri finiranno per capire tutti i comportamenti umani.

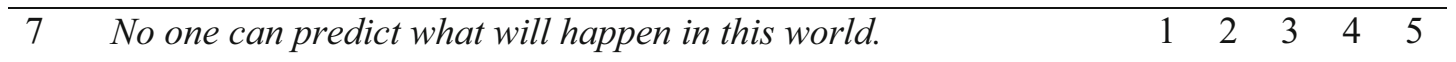
Nessuno può prevedere cosa accadrà in questo mondo.

\begin{tabular}{lllllll}
\hline 8 & People must take full responsibility for any bad choices they & 1 & 2 & 3 & 4 & 5
\end{tabular} make.

Le persone si devono assumere la piena responsabilità di tutte le 
scelte sbagliate che fanno.

$9 \quad$ Fate already has a plan for everyone.

$\begin{array}{lllll}1 & 2 & 3 & 4 & 5\end{array}$

Il destino ha già un piano per tutti.

10 Your genes determine your future.

$\begin{array}{lllll}1 & 2 & 3 & 4 & 5\end{array}$

I tuoi geni determinano il tuo futuro.

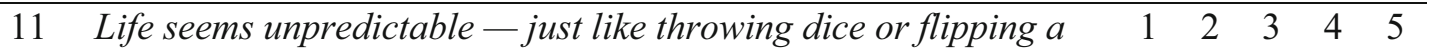
coin.

La vita sembra imprevedibile, proprio come lanciare i dadi o una moneta.

12 People can overcome any obstacles if they truly want to. $\begin{array}{lllll}1 & 2 & 3 & 4 & 5\end{array}$

Le persone possono superare qualsiasi ostacolo se lo vogliono veramente.

13 Whatever will be, will be-there's not much you can do about it. $\quad \begin{array}{llllll}1 & 2 & 3 & 4 & 5\end{array}$ Sarà quel che sarà, non c'è molto che tu possa fare a proposito.

14 Science has shown how your past environment created your $\quad$\begin{tabular}{llllll}
\hline 1 & 2 & 3 & 4 & 5
\end{tabular}
current intelligence and personality.

La scienza ha dimostrato come il tuo ambiente passato ha creato la tua attuale intelligenza e personalità.

15 People are unpredictable. 1128 \begin{tabular}{llll}
\hline & 3 & 4 & 5
\end{tabular}

Le persone sono imprevedibili.

16 Criminals are totally responsible for the bad things they do. $\quad \begin{array}{lllll}2 & 2 & 3 & 4 & 5\end{array}$

I criminali sono totalmente responsabili delle cose cattive che fanno.

17 Whether people like it or not, mysterious forces seem to move $\quad \begin{array}{lllll}1 & 2 & 3 & 4 & 5\end{array}$ their lives.

Che piaccia o no alle persone, forze misteriose sembrano governare le loro vite.

18 As with other animals, human behavior always follows the laws \begin{tabular}{llllll}
\hline & 2 & 3 & 4 & 5
\end{tabular} of nature.

Come per gli altri animali, il comportamento umano segue sempre le leggi della natura.

19 Life is hard to predict because it is almost totally random. $\quad \begin{array}{lllll}1 & 2 & 3 & 4 & 5\end{array}$ La vita è difficile da prevedere perché è quasi totalmente casuale. 
Table 6 Spearman's rho zero-order and partial correlations after controlling for gender and age $(n=138)$

\begin{tabular}{|c|c|c|c|c|c|c|c|c|c|c|c|c|c|c|}
\hline \multicolumn{15}{|l|}{ Free Will } \\
\hline & 1 & 2 & 3 & 4 & 5 & 6 & 7 & 8 & 9 & 10 & 11 & 12 & 13 & 14 \\
\hline Item 4 & & 0.99 & 0.72 & 0.6 & 0.95 & 0.69 & 0.59 & 0.38 & 0.36 & 0.19 & 0.26 & 0.19 & 0.07 & -0.03 \\
\hline Item 8 & 0.99 & & 0.73 & 0.61 & 0.95 & 0.7 & 0.58 & 0.37 & 0.35 & 0.17 & 0.25 & 0.19 & 0.06 & -0.05 \\
\hline Item 12 & 0.72 & 0.73 & & 0.68 & 0.69 & 0.97 & 0.66 & 0.35 & 0.4 & -0.01 & 0.24 & 0.26 & -0.09 & 0.01 \\
\hline Item 16 & 0.6 & 0.61 & 0.68 & & 0.59 & 0.69 & 0.89 & 0.37 & 0.4 & 0.08 & 0.21 & 0.25 & 0.08 & 0.04 \\
\hline Item 21 & 0.95 & 0.95 & 0.69 & 0.59 & & 0.66 & 0.56 & 0.34 & 0.34 & 0.17 & 0.22 & 0.16 & 0.11 & -0.04 \\
\hline Item 23 & 0.69 & 0.7 & 0.97 & 0.68 & 0.66 & & 0.66 & 0.32 & 0.37 & -0.01 & 0.21 & 0.26 & -0.1 & -0.01 \\
\hline Item 26 & 0.59 & 0.59 & 0.66 & 0.89 & 0.57 & 0.66 & & 0.38 & 0.45 & 0.11 & 0.27 & 0.25 & 0.06 & 0.07 \\
\hline Self & 0.38 & 0.37 & 0.35 & 0.38 & 0.35 & 0.32 & 0.39 & & 0.77 & -0.12 & 0.58 & 0.52 & -0.28 & 0.24 \\
\hline Other & 0.36 & 0.36 & 0.4 & 0.4 & 0.35 & 0.37 & 0.45 & 0.77 & & -0.23 & 0.52 & 0.56 & -0.34 & 0.23 \\
\hline $\mathrm{AG}$ & 0.18 & 0.17 & -0.01 & 0.08 & 0.17 & -0.01 & 0.1 & -0.12 & -0.24 & & -0.04 & -0.33 & 0.59 & -0.02 \\
\hline $\mathrm{AC}$ & 0.26 & 0.26 & 0.25 & 0.22 & 0.23 & 0.22 & 0.28 & 0.58 & 0.53 & -0.04 & & 0.19 & -0.2 & 0.22 \\
\hline EX & 0.2 & 0.2 & 0.26 & 0.25 & 0.16 & 0.26 & 0.25 & 0.52 & 0.56 & -0.33 & 0.19 & & -0.34 & 0.34 \\
\hline NEU & 0.07 & 0.06 & -0.09 & 0.08 & 0.11 & -0.1 & 0.06 & -0.27 & -0.34 & 0.59 & -0.2 & -0.34 & & -0.07 \\
\hline SS & -0.03 & -0.05 & 0 & 0.04 & -0.04 & -0.02 & 0.06 & 0.24 & 0.22 & -0.02 & 0.21 & 0.34 & -0.06 & \\
\hline
\end{tabular}

Fatalistic Determinism

\begin{tabular}{|c|c|c|c|c|c|c|c|c|c|c|c|c|}
\hline & 1 & 2 & 3 & 4 & 5 & 6 & 7 & 8 & 9 & 10 & 11 & 12 \\
\hline Item 1 & & 0.54 & 0.99 & 0.52 & 0.51 & 0.01 & 0.05 & 0.1 & 0.06 & -0.09 & 0.08 & -0.12 \\
\hline Item 5 & 0.54 & & 0.53 & 0.99 & 0.97 & 0.06 & 0.12 & -0.02 & 0.03 & 0.03 & -0.04 & -0.14 \\
\hline Item 9 & 0.99 & 0.53 & & 0.52 & 0.51 & 0.01 & 0.05 & 0.1 & 0.06 & -0.09 & 0.07 & -0.11 \\
\hline Item 13 & 0.53 & 0.99 & 0.53 & & 0.98 & 0.05 & 0.12 & -0.03 & 0.02 & 0.03 & -0.05 & -0.12 \\
\hline Item 17 & 0.51 & 0.97 & 0.51 & 0.98 & & 0.04 & 0.13 & -0.05 & 0.01 & 0.05 & -0.08 & -0.09 \\
\hline Self & 0.01 & 0.06 & 0.01 & 0.06 & 0.04 & & 0.77 & -0.12 & 0.58 & 0.52 & -0.28 & 0.24 \\
\hline Other & 0.05 & 0.12 & 0.05 & 0.12 & 0.13 & 0.77 & & -0.23 & 0.52 & 0.56 & -0.34 & 0.23 \\
\hline $\mathrm{AG}$ & 0.11 & -0.01 & 0.1 & -0.02 & -0.05 & -0.12 & -0.24 & & -0.04 & -0.33 & 0.59 & -0.02 \\
\hline $\mathrm{AC}$ & 0.06 & 0.03 & 0.06 & 0.02 & 0.01 & 0.58 & 0.53 & -0.04 & & 0.19 & -0.2 & 0.22 \\
\hline EX & -0.09 & 0.03 & -0.09 & 0.04 & 0.06 & 0.52 & 0.56 & -0.33 & 0.19 & & -0.34 & 0.34 \\
\hline NEU & 0.08 & -0.03 & 0.07 & -0.05 & -0.08 & -0.27 & -0.34 & 0.59 & -0.2 & -0.34 & & -0.07 \\
\hline SS & -0.11 & -0.13 & -0.1 & -0.12 & -0.08 & 0.24 & 0.22 & -0.02 & 0.21 & 0.34 & -0.06 & \\
\hline
\end{tabular}

Scientific Determinism

\begin{tabular}{|c|c|c|c|c|c|c|c|c|c|c|c|c|c|c|}
\hline & 1 & 2 & 3 & 4 & 5 & 6 & 7 & 8 & 9 & 10 & 11 & 12 & 13 & 14 \\
\hline Item 2 & & 0.63 & 0.94 & 0.63 & 0.63 & 0.92 & 0.62 & 0.51 & 0.45 & 0.11 & 0.31 & 0.42 & 0.03 & 0.14 \\
\hline Item 6 & 0.63 & & 0.62 & 0.95 & 0.99 & 0.62 & 0.99 & 0.46 & 0.43 & 0.06 & 0.25 & 0.34 & 0.01 & -0.06 \\
\hline Item 10 & 0.94 & 0.62 & & 0.61 & 0.62 & 0.9 & 0.61 & 0.47 & 0.44 & 0.06 & 0.26 & 0.42 & 0.01 & 0.08 \\
\hline Item 14 & 0.63 & 0.95 & 0.61 & & 0.95 & 0.65 & 0.95 & 0.46 & 0.38 & 0.06 & 0.27 & 0.33 & 0 & -0.02 \\
\hline Item 18 & 0.63 & 0.99 & 0.62 & 0.95 & & 0.62 & 0.99 & 0.46 & 0.43 & 0.06 & 0.25 & 0.34 & 0.01 & -0.06 \\
\hline Item 22 & 0.92 & 0.63 & 0.9 & 0.65 & 0.63 & & 0.62 & 0.49 & 0.41 & 0.12 & 0.32 & 0.46 & 0 & 0.14 \\
\hline Item 24 & 0.62 & 0.99 & 0.62 & 0.95 & 0.99 & 0.62 & & 0.45 & 0.42 & 0.07 & 0.24 & 0.33 & 0.03 & -0.07 \\
\hline Self & 0.5 & 0.45 & 0.46 & 0.45 & 0.45 & 0.48 & 0.44 & & 0.77 & -0.12 & 0.58 & 0.52 & -0.28 & 0.24 \\
\hline Other & 0.45 & 0.43 & 0.44 & 0.38 & 0.43 & 0.41 & 0.41 & 0.77 & & -0.23 & 0.52 & 0.56 & -0.34 & 0.23 \\
\hline $\mathrm{AG}$ & 0.11 & 0.06 & 0.06 & 0.06 & 0.06 & 0.12 & 0.07 & -0.12 & -0.24 & & -0.04 & -0.33 & 0.59 & -0.02 \\
\hline $\mathrm{AC}$ & 0.31 & 0.25 & 0.26 & 0.27 & 0.25 & 0.32 & 0.24 & 0.58 & 0.53 & -0.04 & & 0.19 & -0.2 & 0.22 \\
\hline EX & 0.41 & 0.34 & 0.41 & 0.32 & 0.34 & 0.45 & 0.33 & 0.52 & 0.56 & -0.33 & 0.19 & & -0.34 & 0.34 \\
\hline NEU & 0.02 & 0.01 & 0.01 & -0.01 & 0.01 & 0 & 0.02 & -0.27 & -0.34 & 0.59 & -0.2 & -0.34 & & -0.07 \\
\hline SS & 0.13 & -0.07 & 0.07 & -0.03 & -0.07 & 0.13 & -0.08 & 0.24 & 0.22 & -0.02 & 0.21 & 0.34 & -0.06 & \\
\hline
\end{tabular}


Table 6 (continued)

\begin{tabular}{|c|c|c|c|c|c|c|c|c|c|c|c|c|c|c|c|}
\hline \multicolumn{16}{|c|}{ Unpredictability } \\
\hline & 1 & 2 & 3 & 4 & 5 & 6 & 7 & 8 & 9 & 10 & 11 & 12 & 13 & 14 & 15 \\
\hline Item 3 & & 0.99 & 0.9 & 0.99 & 0.99 & 0.99 & 0.9 & 0.92 & 0.02 & 0.01 & 0.18 & 0.02 & -0.06 & 0.07 & -0.12 \\
\hline Item 7 & 0.99 & & 0.9 & 0.99 & 0.99 & 0.99 & 0.9 & 0.93 & 0.02 & 0.01 & 0.18 & 0.01 & -0.06 & 0.07 & -0.13 \\
\hline Item 11 & 0.9 & 0.9 & & 0.9 & 0.9 & 0.9 & 0.99 & 0.85 & -0.02 & -0.01 & 0.1 & -0.08 & -0.04 & 0.05 & -0.07 \\
\hline Item 15 & 0.99 & 0.99 & 0.9 & & 0.99 & 0.99 & 0.9 & 0.94 & 0.03 & 0.02 & 0.19 & 0.01 & -0.07 & 0.08 & -0.13 \\
\hline Item 19 & 0.99 & 0.99 & 0.9 & 0.99 & & 0.99 & 0.9 & 0.92 & 0.02 & 0.01 & 0.18 & 0.02 & -0.06 & 0.07 & -0.12 \\
\hline Item 20 & 0.99 & 0.99 & 0.9 & 0.99 & 0.99 & & 0.9 & 0.93 & 0.02 & 0.01 & 0.18 & 0.01 & -0.06 & 0.07 & -0.13 \\
\hline Item 25 & 0.9 & 0.9 & 0.99 & 0.9 & 0.9 & 0.9 & & 0.85 & -0.02 & -0.01 & 0.1 & -0.08 & -0.04 & 0.05 & -0.07 \\
\hline Item 27 & 0.92 & 0.93 & 0.85 & 0.94 & 0.92 & 0.93 & 0.85 & & 0 & 0.01 & 0.16 & -0.03 & -0.04 & 0.04 & -0.12 \\
\hline Self & 0.03 & 0.02 & -0.02 & 0.03 & 0.03 & 0.02 & -0.02 & 0.01 & & 0.77 & -0.12 & 0.58 & 0.52 & -0.28 & 0.24 \\
\hline Other & 0.02 & 0.02 & -0.01 & 0.02 & 0.02 & 0.02 & -0.01 & 0.02 & 0.77 & & -0.23 & 0.52 & 0.56 & -0.34 & 0.23 \\
\hline AG & 0.18 & 0.18 & 0.1 & 0.19 & 0.18 & 0.18 & 0.1 & 0.15 & -0.12 & -0.24 & & -0.04 & -0.33 & 0.59 & -0.02 \\
\hline $\mathrm{AC}$ & 0.02 & 0.01 & -0.08 & 0.01 & 0.02 & 0.01 & -0.08 & -0.03 & 0.58 & 0.53 & -0.04 & & 0.19 & -0.2 & 0.22 \\
\hline EX & -0.06 & -0.06 & -0.04 & -0.06 & -0.06 & -0.06 & -0.04 & -0.04 & 0.52 & 0.56 & -0.33 & 0.19 & & -0.34 & 0.34 \\
\hline NEU & 0.07 & 0.07 & 0.05 & 0.08 & 0.07 & 0.07 & 0.05 & 0.05 & -0.27 & -0.34 & 0.59 & -0.2 & -0.34 & & -0.07 \\
\hline SS & -0.12 & -0.13 & -0.07 & -0.13 & -0.12 & -0.13 & -0.07 & -0.12 & 0.24 & 0.22 & -0.02 & 0.21 & 0.34 & -0.06 & \\
\hline
\end{tabular}

Note. Values in the lower triangle represent zero-order correlations, values in the upper triangle represent correlations obtained by partialling out the effects of gender and age

Funding No funding was received.

Data Availability The datasets generated during and/or analysed during the current study are available from the corresponding author upon reasonable request.

\section{Declarations}

Conflict of Interest On behalf of all authors, the corresponding author states that there is no conflict of interest.

Ethics Approval The study was approved by an institutional research ethics committee at S\&P Statistics \& Psychometrics Ltd., and the study was performed in accordance with the ethical standards as laid down in the 1964 Declaration of Helsinki and its later amendments or comparable ethical standards.

Consent Informed consent was obtained from all individual participants included in the study.

Open Access This article is licensed under a Creative Commons Attribution 4.0 International License, which permits use, sharing, adaptation, distribution and reproduction in any medium or format, as long as you give appropriate credit to the original author(s) and the source, provide a link to the Creative Commons licence, and indicate if changes were made. The images or other third party material in this article are included in the article's Creative Commons licence, unless indicated otherwise in a credit line to the material. If material is not included in the article's Creative Commons licence and your intended use is not permitted by statutory regulation or exceeds the permitted use, you will need to obtain permission directly from the copyright holder. To view a copy of this licence, visit http://creativecommons.org/licenses/by/4.0/.

\section{References}

Aluja, A., \& García, Ó., García, L. F. (2002). A comparative study of Zuckerman's three structural models for personality through the NEO-PI-R, ZKPQ-III-R, EPQ-RSand Goldberg's 50bipolaradjectives. Personality and Individual Differences, 33(5), 713-725

Asparouhov, T., \& Muthén, B. (2009). Exploratory Structural Equation Modeling. Structural Equation Modeling: A Multidisciplinary Journal, 16(3), 397-438, https://doi.org/10.1080/ 10705510903008204

Baumeister, R. F. (2017). Addiction, cigarette smoking, and voluntary control of action: Do cigarette smokers lose their free will? Addictive Behaviors Reports, 5, 67-84. https://doi.org/10.1016/j.abrep.2017. 01.003

Baumeister, R. F., \& Monroe, A. E. (2014). Chapter one -recent research on free will: Conceptualizations, beliefs, and processes. In J. M. Olson \& M. P. Zanna (Eds.), Advances in experimental social psychology (Vol. 50, pp. 1-52). Academic Press. https://doi.org/ 10.1016/B978-0-12-800284-1.00001-1

Baumeister, R. F., Masicampo, E. J., \& DeWall, C. N. (2009). Prosocial benefits of feeling free: Disbelief in free will increases aggression and reduces helpfulness. Personality and Social Psychology Bulletin, 35(2), 260-268. https://doi.org/10.1177/ 0146167208327217

Baumeister, R. F., Sparks, E. A., Stillman, T. F., \& Vohs, K. D. (2008). Free will in consumer behavior: Self-control, ego depletion, and choice. Journal of Consumer Psychology, 18(1), 4-13. https://doi. org/10.1016/j.jcps.2007.10.002

Baumgartner, H., \& Steenkamp, J.-B. E. M. (2001). Response styles in marketing research: A cross-National Investigation. Journal of Marketing Research, 38(2), 143-156. https://doi.org/10.1509/jmkr. 38.2.143.18840 
Berniunas, R., Beinorius, A., Dranseika, V., Silius, V., \& Rimkevicius, P. (2021). The weirdness of belief in free will. Consciousness and Cognition, 87, 103054. https://doi.org/10.1016/j.concog.2020. 103054

Boudesseul, J., Lantian, A., Cova, F., \& Bègue, L. (2016). Free love? On the relation between belief in free will, determinism, and passionate love. Consciousness and Cognition, 56, 47-59. https://doi.org/10. 1016/j.concog.2016.09.003

Bowlby, J. (1969). Attachment and Loss, Vol 1: Loss. Basic Books

Candilera, G. (2007). 9 attachment profile (9AP). Manuale e norme [9 attachment profile (9AP). Manual and norms]. Scione Editore

Caspar, E., Verdin, O., Rigoni, D., Cleeremans, A., \& Klein, O. (2017). What do you believe in? French translation of the FADplusto assess beliefs in free will and determinism and their relationship with religious practices and personality traits. Psychologica Belgica, 57, 116. https://doi.org/10.5334/pb.321

Chalmers, R. P., \& Flora, D. B. (2015). Faoutlier: An R package for detecting influential cases in exploratory and confirmatory factor analysis. Applied Psychological Measurement, 39(7), 573-574. https://doi.org/10.1177/0146621615597894

Chen, F. F. (2007). Sensitivity of goodness of fit indexes to lack of measurement invariance. Structural Equation Modeling: A Multidisciplinary Journal, 14(3), 464-504. https://doi.org/10.1080/ 10705510701301834

Cheung, G. W., \& Rensvold, R. B. (2002). Evaluating goodness-offitindexes for testing measurement invariance. Structural Equation Modeling, 9, 233-255. https://doi.org/10.1207/ S15328007SEM0902 5

Clark, C. J., Baumeister, R. F., \& Ditto, P. H. (2017). Making punishment palatable: Belief in free will alleviates punitive distress. Consciousness and Cognition, 51, 193-211. https://doi.org/10. 1016/j.concog.2017.03.010

Crivellaro, F., \& Sperduti, A. (2014). Accepting and understanding evolution in Italy: A case study from a selected public attending a Darwin day celebration. Evolution: Education and Outreach, 7, 13. https://doi.org/10.1186/s12052-014-0013-4

Edwards, J. R. (2008). To prosper, organizational psychology should ... overcome methodological barriers to progress. Journal of Organizational Behavior, 29(4), 469-491. https://doi.org/10.1002/ job.529

Feltz, A. (2015). Experimental philosophy of actual and counterfactual free will intuitions. Consciousness and Cognition, 36, 113-130. https://doi.org/10.1016/j.concog.2015.06.001

Fino, E., Iliceto, P., Sabatello, U., Petrucci, F., \& Candilera, G. (2014). Self/other perception mediates between personality and suicidal ideation in young adults. The European Journal of Psychiatry, 28(2), 104-113

Flora, D. B., \& Curran, P. J. (2005). An empirical evaluation of alternative methods of estimation for confirmatory factor analysis with ordinal data. Psychological Methods, 9(4), 466-491. https://doi. org/10.1037/1082-989X.9.4.466

Fu, J., Zhao, Y., Feng, X., Wang, Y., Yu, Z., Hua, L., Wang, S., \& Li, J. (2021). How is fatalistic determinism linked to depression? The mediating role of self-controland resilience. Personality and Individual Differences, 180, 110992. https://doi.org/10.1016/j.paid. 2021.110992

Green, S. B., \& Yang, Y. (2009). Reliability of summed item scores using structural equation modeling: An alternative to coefficient alpha. Psychometrika, 74(1), 155-167. https://doi.org/10.1007/s11336008-9099-3

Iliceto, P., D'Antuono, L., Bowden-Jones, H., Giovani, E., Giacolini, T., Candilera, G., Sabatello, U., \& Panksepp, J. (2016). Brain emotion systems, personality, hopelessness, self/other perception, and gambling cognition: A structural equation model. Journal of Gambling Studies, 32(1), 157-169. https://doi.org/10.1007/s10899-015-95430
Iliceto, P., Fino, E., Schiavella, M., \& Candildera, G. (2020). Individual differences in interpersonal security predict suicidal ideation and problem gambling. Personality and Individual Differences, 162, 110031. https://doi.org/10.1016/j.paid.2020.110031

Kane, R. (1996). The significance of free will. Oxford University Press

Kenny, D. A. (2015). Measuring model fit. http://davidakenny.net/cm/fit. htm

Kondratowicz-Nowak, B., Duda, J., Wierzbicki, J., \& Zawadzka, A. M. (2018). The free will and determinism plus (FADplus) scale: The validity and reliability of the polish adaptation. Roczniki Psychologiczne/Annalsof Psychology, 21(4), 345-364. https://doi. org/10.18290/rpsych.2018.21.4-4

Li, C.-H. (2016). Confirmatory factor analysis with ordinal data: Comparing robust maximum likelihood and diagonally weighted least squares. Behavior Research Methods, 48(3), 936-949. https:// doi.org/10.3758/s13428-015-0619-7

Li, J., Zhao, Y., Lin, L., Chen, J., \& Wang, S. (2018). The freedom to persist: Belief in free will predicts perseverance for long term goals among Chinese adolescents. Personality and Individual Differences, 121, 7-10. https://doi.org/10.1016/j.paid.2017.09.011

Lim, D., \& Chen, J. (2018). Is compatibilism intuitive? Philosophical Psychology, 31(6), 878-897. https://doi.org/10.1080/09515089. 2018.1459534

Marsh, H. W., Morin, A. J. S., Parker, P. D., Kaur, G. (2014). Exploratory structural equation modeling: an integration of the best features of exploratory and confirmatory factor analysis. Annual Review of Clinical Psychology, 10, 85-110. https://doi.org/10.1146/annurevclinpsy-032813-153700

McHorney, C. A., \& Tarlov, A. R. (1995). Individual-patientmonitoring in clinical practice: Are available health status surveys adequate? Quality of Life Research, 4(4), 293-307. https://doi.org/10.1007/ BF01593882

Muraven, M. (2010). Building self-controlstrength: Practicing selfcontrolleads to improved self-controlperformance. Journal of Experimental Social Psychology, 46(2), 465-468. https://doi.org/ 10.1016/j.jesp.2009.12.011

Muthén, B., Muthén, L., \& Asparouhov, L. (2015). Estimator choices with categorical outcomes. Muthén \& Muthén. https://www. statmodel.com/download/EstimatorChoices.pdf

Paulhus, D. L., \& Carey, J. M. (2011). The FAD-plus: Measuring lay beliefs regarding free will and related constructs. Journal of Personality Assessment, 93(1), 96-104. https://doi.org/10.1080/ 00223891.2010 .528483

Pek, J., \& MacCallum, R. C. (2011). Sensitivity analysis in structural equation models: Cases and their influence. Multivariate Behavioral Research, 46(2), 202-228. https://doi.org/10.1080/ 00273171.2011.561068

Petrillo, J., Cano, S. J., McLeod, L. D., \& Coon, C. D. (2015). Using classical test theory, item response theory, and Rasch measurement theory to evaluate patient-reportedoutcome measures: A comparison of worked examples. Value in Health: The Journal of the International Society for Pharmacoeconomics and Outcomes Research, 18(1), 25-34. https://doi.org/10.1016/j.jval.2014.10.005

Podsakoff, P. M., MacKenzie, S. B., Lee, J.-Y., \& Podsakoff, N. P. (2003). Common method biases in behavioral research: A critical review of the literature and recommended remedies. Journal of Applied Psychology, 88(5), 879-903. https://doi.org/10.1037/ 0021-9010.88.5.879

Podsakoff, P. M., MacKenzie, S. B., \& Podsakoff, N. P. (2012). Sources of method Bias in social science research and recommendations on how to control it. Annual Review of Psychology, 63, 539-569. https://doi.org/10.1146/annurev-psych-120710-100452

Putnick, D. L., \& Bornstein, M. H. (2016). Measurement invariance conventions and reporting: The state of the art and future directions for psychological research. Developmental Review : DR, 41, 71-90. https://doi.org/10.1016/j.dr.2016.06.004 
Revelle, W. (2020). Psych: Procedures for psychological, psychometric, and personality research (version 1.9.12.31). The Comprehensive $R$ Archive Network https://CRAN.R-project.org/package=psych

R Core Team. (2019). R A Language and Environment for Statistical Computing. $R$ Foundation for Statistical Computing, Vienna, Austria.

Rigoni, D., Braem, S., Pourtois, G., \& Brass, M. (2016). Fake feedback on pain tolerance impacts proactive versus reactive control strategies. Consciousness and Cognition, 42, 366-373. https://doi.org/10. 1016/j.concog.2016.04.015

Rosseel, Y. (2012). Lavaan: An R package for structural equation modeling. Journal of Statistical Software, 48(2), 1-36

Stroessner, S. J., \& Green, C. W. (1990). Effects of belief in free will or determinism on attitudes toward punishment and locus of control. The Journal of Social Psychology, 130(6), 789-799. https://doi.org/ 10.1080/00224545.1990.9924631

Svetina, D., Rutkowski, L., \& Rutkowski, D. (2019). Multiplegroupinvariance with categorical outcomes using updated guidelines: An illustration using Mplus and the lavaan/
semToolspackages. Structural Equation Modeling: A Multidisciplinary Journal, 27(1), 1-20. https://doi.org/10.1080/ 10705511.2019.1602776

Tóth-Király, I., Bõthe, B., Rigó, A., \& Orosz, G. (2017). An illustration of the exploratory structural equation modeling (ESEM) framework on the passion scale. Frontiers in Psychology, 8. https://doi.org/10. 3389/fpsyg.2017.01968

Vonasch, A. J., Clark, C. J., Lau, S., Vohs, K. D., \& Baumeister, R. F. (2017). Ordinary people associate addiction with loss of free will. Addictive Behaviors Reports, 5, 56-66. https://doi.org/10.1016/j. abrep.2017.01.002

Zhao, X., Liu, L., Zhang, X., Shi, J., \& Huang, Z. (2014). The effect of belief in free will on prejudice. PLoS One, 9(3), e91572. https://doi. org/10.1371/journal.pone.0091572

Publisher's Note Springer Nature remains neutral with regard to jurisdictional claims in published maps and institutional affiliations. 